Escuela de Ciencias Sociales y Humanidades, UNED, Costa Rica https://revistas.uned.ac.cr/index.php/espiga ISSN: 1409-4002 • e-ISSN: 2215-454X

\title{
Muerte y luto en Mourning picture: conversaciones entre un pintor y su hija
}

La pintura es poesía muda y la poesía es pintura que habla.

Plutarco

\section{Death and Mourning in Mourning picture: Conversations Between a Painter and his Daughter}

La morte et le deuil dans Morning picture: conversations entre un peintre et sa fille

Ileana Molina-Espinoza *

Orcid: 0000-0002-2567-9166

Recibido: 30 de marzo de 2021 • Aceptado: 16 de junio de 2021

* Bachillerato en Inglés y maestría en literatura inglesa, de la Universidad de Costa Rica (UCR), de Costa Rica. Docente e investigadora de la Escuela de Lenguas Modernas de la UCR. Correo: molinae3@gmail.com 


\section{Resumen}

En 1890, Edwin Romanzo Elmer pinta Mourning picture. Setenta y cinco años más tarde, la poeta Adrienne Rich escribe un poema acerca de la pintura. Ambos textos presentan acercamientos muy distintos a la vivencia de la muerte y el duelo, los cuales serán analizados en este ensayo. Para el análisis comparativo de los textos propuestos, se utilizará como marco conceptual la écfrasis, entendida como la representación verbal de una representación visual. Se analizaron ambos textos por separado iniciando con el objeto plástico como composición pictórica. El poema que Rich escribe a partir de esta pintura se analiza con herramientas propias del análisis literario, tales como los recursos estructurales y estilísticos presentes en la construcción del poema, en la relación dialógica que este establece con la pintura.

Palabras clave: écfrasis, duelo, pintura, poema.

\section{Abstract}

In 1890, Edwin Romanzo Elmer painted Mourning picture. Seventy-five years later, the poet Adrienne Rich wrote a poem about that painting. Both texts present very different approaches to the experience of death and mourning, which will be analyzed in this essay. For the comparative analysis of the proposed texts, ecphrasis, understood as the verbal depiction of a visual representation, will be used as a conceptual framework. Both texts were analyzed separately starting with the plastic object as a pictorial composition. The poem that Rich writes from this painting is analyzed with tools of literary analysis, such as the structural and stylistic resources present in the structure of the poem, in the dialogical relationship that it establishes with the painting.

Keywords: ecphrasis, mourning, painting, poem.

\section{Résumé}

En 1890, Edwin Romanzo Elmer a peint Morning picture et soixante-cinq ans après, la poétesse Adrienne Rich a écrit un poème à propos de la peinture. Les deux œuvres offrent une approche très différente sur la mort et le deuil, lesquels sont étudiés par le biais de l'analyse comparative dans le cadre conceptuel de l'ekphrasis, laquelle est définie comme la description verbale d'une représentation visuelle. Les deux textes ont été analysés individuellement en commençant pour l'objet plastique en tant que composition picturale. Le poème écrit par Rich à partir de la peinture est analysé moyennant les outils de l'analyse littéraire tels que les ressources structurelles et stylistiques présentes dans la construction du poème en rapport dialogique qui a été établi avec la peinture.

Mots-clés: deuil, ekphrasis, peinture, poème. 


\section{Introducción}

¿Cómo se representan experiencias tales como la muerte y el duelo en la pintura y la poesía? ¿Pueden estas expresiones artísticas establecer un diálogo acerca de una vivencia tan dolorosa? El siguiente análisis comparativo explora la naturaleza de esta conversación a través de dos textos: uno pictórico, del pintor Edwin Romanzo (ver anexo 1), y otro poético, de la escritora Adrienne Rich (ver anexo 2).

Edwin Romanzo Elmer (1850-1923) fue un pintor estadounidense de retratos, géneros y bodegones. Nació en Ohio en 1850, el más joven de doce hijos en una familia de granjeros que se mudó a Buckland, Massachusetts, cuando Edwin tenía seis años. Elmer perfeccionó su arte en Buckland y vivió la mayor parte de su vida en Ashfield, Massachusetts. Aunque estudió arte de manera privada, en Nueva York, no fue un pintor reconocido en su época. Entre sus pocas obras se encuentran una escena en tiza de un huerto de manzanas de Buckland, fechada en 1906, y Magic Glasses, una pintura de 1891 que está actualmente en el Museo Shelburne de Vermont. Después de algunos intentos fracasados como pintor, se dedicó principalmente a las labores agrícolas. Fue diagnosticado con cáncer de abdomen y, al contraer una gran deuda con el hospital, se suicidó en 1923.

Por otro lado, la poeta Adrienne Cecile Rich (16 de mayo de 1929, Baltimore, Maryland - 27 de marzo de 2012, Santa Mónica, California), más conocida como Adrienne Rich, fue una poeta, intelectual, crítica, feminista y activista lesbiana estadounidense. Durante su vida, produjo numerosos volúmenes de poesía que trazan una transformación estilística de la poesía formal, bien elaborada, con un estilo personal y poderoso.

Ampliamente leída y reconocida, durante décadas Rich fue una de las escritoras más influyentes del movimiento feminista y una de las intelectuales estadounidenses más conocidas. Triplemente marginada, como mujer, lesbiana y judía, Rich estaba comprometida en su poesía, y en sus muchos ensayos, con las políticas de identidad.

Aunque la poesía de Rich ha sido ampliamente analizada y discutida, el poema ecfrástico que escribió sobre la pintura Mourning Picture no ha recibido mucha atención por parte de estudiosos de la literatura. Este poema entrelaza el objeto plástico de un pintor casi desconocido con el texto poético de una escritora internacionalmente aplaudida, en una conversación en torno a un tema trágico: la muerte y el duelo de una hija.

Para el análisis comparativo de los textos propuestos, se utilizará como marco conceptual la Écfrasis. Existen varias definiciones de esta metodología 
comparatística, como se evidencia en el artículo «Lectura iconotextual: la écfrasis metaléptica como recurso representacional en Una Novelista en el Museo del Louvre, de Zoé Valdés» de Iraida Lisandra Bárzaga Morales, quien señala tres. Leo Spitzer define la écfrasis como «la descripción poética de una obra de arte pictórica o escultórica», mientras que James Heffernan se refiere a esta como «la representación verbal de una representación visual»1. Claus Clüver, por otro lado, la define como «la representación verbal de un texto real o ficticio compuesto en un sistema sígnico no verbal» ${ }^{2}$. Las tres definiciones coinciden en el carácter relacional del texto verbal con el objeto plástico. De acuerdo con Luz Aurora Pimentel en «Écfrasis y lecturas iconotextuales», el proceso de Écfrasis «establece una relación tanto referencial como representacional con un objeto plástico que el propio texto propone como autónomo, como otro con respecto al discurso que intenta representarlo» ${ }^{3}$.

Dado que el texto verbal asume la representación de un objeto de artes visuales, se establece una relación intertextual. De acuerdo con Marta Plaza Velazco, en su artículo «Poesía que es pintura. Écfrasis literaria en exposición de Olvido García Valdés»:

La écfrasis supone la puesta en relación de un texto literario con una obra de arte, por eso puede ser entendida como una práctica intertextual (al tratarse de un texto que toma como referencia a otro texto, aunque se trate de un texto no verbal) o intermedial (ya que relaciona textos de dos sistemas semióticos diferentes). ${ }^{4}$

Esta relación intermedial e intersemiótica entre el objeto plástico y el texto verbal es consecuencia de la construcción de sentido en dos medios artísticos diferentes (la pintura y el poema), que funcionan como dos textos que se entrelazan, donde uno refiere al otro y viceversa en un juego de espejos. De esta manera, el objeto plástico representado entra en una compleja relación de identidad y otredad con el texto poético y con el contexto en el que la écfrasis se inscribe. Como afirma Pimentel en el artículo previamente mencionado: «Destaca, asimismo, el carácter doblemente representacional de la écfrasis, puesto que se trata de la representación verbal de una representación visual... el texto verbal representa al "texto" no verbal, compuesto en un sistema de signos no verbal» ${ }^{5}$.

\footnotetext{
1 Iraida Lisandra Bárzaga Morales, «Lectura iconotextual: la écfrasis metaléptica como recurso representacional en Una Novelista en el Museo del Louvre, de Zoé Valdés». Revista Comunicación 27, n. $^{\circ} 1$ (2018): 2.

2 Ibíd.

${ }^{3}$ Luz Aurora Pimentel, «Écfrasis y lecturas iconotextuales», Revista de teoría literaria y literatura comparada Poligrafías, n. ${ }^{\circ} 4$ (2003): 205.

${ }^{4}$ Marta Plaza Velasco, «Poesía que es pintura. Écfrasis literaria en exposición de Olvido García Valdés», Actio Nova: Revista de teoría de la literatura y literatura comparada, n. ${ }^{2}$ (2018): 37.

5 Pimentel, «Écfrasis y lecturas..., 206.
} 
Dado que la écfrasis implica la representación de otra representación, se da también una relación de mimetismo fundamentada en la imitación. Respecto a este tema, Marta Plaza Velazco apunta, en el artículo antes mencionado, que «al tratarse de la imitación de una imitación de la realidad, como mínimo, se da una doble mímesis («Como el texto ecfrástico representa con palabras una representación plástica, esta mímesis es doble»)»6. Sin embargo, este mimetismo se vuelve «ilusorio» o «ficticio» ya que la «representación verbal toma gradualmente el poder de un objeto que se sostiene por sí mismo y que ya no se apoya en otra representación tangible extra-textual» ${ }^{7}$. De esta manera, la relación que se establece entre la obra visual y el texto escrito crea una resignificación del objeto plástico y una transformación en el texto literario.

Este proceso de resignificación de sentido sucede cuando el poeta selecciona, reorganiza y resignifica el objeto plástico representado al convertirlo en un texto verbal. De igual manera, el investigador también es parte de este proceso de resignificación al «construir sentido» 0 «interpretar» ambos textos por separado y en su relación intertextual. Pimental se refiere a esta dinámica, en el artículo citado anteriormente, al indicar que: «no sólo la representación visual es leída/ escrita-de hecho, descrita-como texto, sino que al entrar en relaciones significantes con el verbal, le añade a este último formas de significación sintética que son del orden de lo icónico y de lo plástico» ${ }^{8}$. Pintura, poema y lector/investigador participan en un diálogo donde pueden interactuar y crear significado, como en una suerte de cajas chinas que contienen y son contenidas a la vez por otras: re-presentación de otras re-presentaciones de duelos lejanos y cercanos.

En «Ecfrasis y lecturas iconotextuales», Pimental señala la diferencia entre los objetos plásticos que pueden ser representados a través de esta metodología; se habla de écfrasis referencial «cuando el objeto plástico tiene una existencia material autónoma, o de écfrasis nocional cuando el objeto "representado" solamente existe en y por el lenguaje, como en el caso del escudo de Aquiles, el cual no existe fuera de la descripción que lo construye» ${ }^{9}$. Dado que el objeto plástico en análisis sí tiene una existencia material, se utilizará la rama de la Écfrasis conocida como «referencial o real».

\section{Desarrollo}

Como se establece en la introducción, este análisis comparativo aborda dos textos, uno pictórico y otro literario, en un diálogo acerca de la muerte y el luto.

\footnotetext{
6 Velasco, «Poesía que es pintura..., 36.

7 lbíd.

8 Pimentel, «Écfrasis y lecturas..., 206.

9 Pimentel, «Écfrasis y lecturas ..., 3.
} 
Poca es la información acerca del pintor Edwin Romanzo Elmer y su pintura Mourning picture (1890). Su trabajo más conocido es precisamente esta pintura, la cual fue descubierta por una sobrina años después de su muerte, cuando finalmente se pudo apreciar su talento. Actualmente, la obra se encuentra en el Museo de Arte del centro educativo Smith College.

La pintura inicialmente no tenía ningún nombre. Posteriormente, se le otorgó el que tiene actualmente, debido a la escena ahí representada. Imagen de luto, que es la traducción en español, representa una escena familiar donde los protagonistas son el pintor mismo, su esposa, Mary Ware Elmer, y su hija, Effie Lillian Elmer, quien había muerto recientemente de apendicitis a la corta edad de 9 años (ver anexo 3). La pintura es, por lo tanto, una elegía visual de Elmer en un intento por recordar y retener a su hija.

Por otro lado, aunque la obra poética de Adrienne Rich ha sido ampliamente abordada por críticos y estudiosos de la literatura, existen pocos artículos del trabajo ecfrástico de Mourning Picture. Este texto es parte de una colección de poemas titulada Collected Early Poems 1950- 1970, publicada en 1950.

Entre los ensayos acerca del poema de Rich, se encuentra Ekphrasis as an Analytical Mode in Biography, de Sue Lovel, el cual compara a la poeta con la figura de Effie Elmer. De acuerdo con la autora, ambos personajes femeninos habitan un espacio de ambivalencia.

«When Rich vacates her voice, Effie occupies it (...) Perhaps, what Rich and Effie share is that sense of standing behind materiality: for Effie, it is the world she haunts but no longer inhabits; for Rich, it is the poem she writes but does not occupy. Though not identically, they are both outside the frame». ${ }^{10}$

De acuerdo con Lovel, tanto Rich como Effie son figuras femeninas empoderadas que, metafóricamente, se posicionan «fuera del marco». Por un lado, Rich fue conocida por su escritura transgresora de normas sociales y Effie, como se verá en el análisis del texto poético, toma el control de la pintura, convirtiéndose en la narradora de su propia muerte.

En su artículo «Remediar el género: ecfrasis, museos y autor(a)referencia», Irene Artigas Albarelli se refiere a la «importancia que la conciencia de genderización tuvo en la obra [de Rich] y cómo su escritura se convirtió en una acción política cultural e imprescindible» ${ }^{11}$. Aunque Artigas no aborda directamente el poema ecfrástico en discusión, si analiza la manera personal en que Rich se relaciona

10 Susan Lovell, «Ekphrasis as an Analytical Mode in Biography: Finding Vida Lahey's Romantic Character». Auto/Biography Studies 28, (2013): 10.

11 Irene Artigas Albarelli, «Remediar el género: ecfrasis, museos y autor(a) referencia». Interférences littéraires/ Literaire interferenties (2017): 164. 
con este proceso creativo, ya que de hecho escribió varios poemas de este tipo: «Para [esta poeta], la écfrasis fue una forma de extender sus objetivos feministas encontrando nuevas visiones (re-visiones) en actos concretos de observación» 12 , añadiendo que dichas producciones son «formas de entrenar al ojo para seleccionar y comprender lo que ella veía de otra manera» ${ }^{13}$.

Esta manera particular de ver es precisamente la que Rich manifiesta en su poesía ecfrástica, ya que ocurre una reconfiguración de la relación entre el sujeto poético y el objeto mirado, con el fin de crear diferentes roles en la política de la «mirada». De acuerdo con Elizabet Loizeaux, citada por Marta Soares en su artículo «Language Cannot Do Everything»:

This «feminist ekphrasis» (...) recognizes that a woman's place as viewer is established within, beside, or in the face of a male-dominated culture, but that the patterns of power and value implicit in a tradition of male artists and viewers can be exposed, used, resisted, and rewritten. ${ }^{14}$

Para Rich, la poesía ecfrástica es una manera de resistir y subvertir percepciones y construcciones patriarcales que han inmovilizado a sujetos femeninos por siglos.

De acuerdo con Soares, la relación dialógica entre pintura y poema es tensa, ya que Effie reclama autonomía rompiendo con el rol pasivo otorgado por su padre: «the poem succeeds in transferring the creator's authority from father to daughter, for the scene is now a projection of Effie's dream (...)»15. Durante las décadas de 1960 y 1970, Rich recurrió a la écfrasis para provocar una revisión cultural de las representaciones femeninas convencionales. Como la misma autora escribió en su poema Planetarium: «What we see, we see/ and seeing is changing» ${ }^{16}$. Es la mirada transformadora de Adrienne Rich la que convoca al lector a examinar la escena de duelo con ojos nuevos; esta vez, a través de los ojos de Effie, reconstruyendo de esta manera la representación de la niña muerta.

Otras autoras que mencionan el poema Mourning Picture son Elizabeth Young en su artículo Mourning Pictures and Magic Glasses. Asimismo, Elizabeth Bergmann Loizeaux aborda esta producción poética de Rich en Women Looking: The Feminist Ekphrasis of Marianne More and Adrienne Rich más que todo desde un punto de vista feminista, ligado con el proceso de re-vision propuesto por Rich para escapar de la mirada masculina. Marta Soares en su artículo

\footnotetext{
12 Ibíd., 173.

13 Ibíd., 174.

14 Marta Soares, «Language Cannot Do Everything": Ekphrasis as a Strategy of Re-vision in Adrienne Rich's

Poetry» (conferencia dada en Turquía en noviembre de 2010): 26.

15 Ibíd., 27.

${ }^{16}$ Adrienne Rich, Poems. (Classic Poetry Series. The World's Poetry Archive, 2012): 34.
} 
«Language Cannot Do Everything: Ekphrasis as a Strategy of Re-vision in Adrienne Rich's Poetry» analiza varios poemas de Rich como una estrategia de la poeta para ir más allá de los límites del lenguaje mismo. El poema de Rich ha sido analizado más que todo desde una perspectiva feminista y revisionista, relacionado con conceptos como la mirada masculina, conocido como «the gaze». A través de este y otros poemas ecfrásticos, Rich logra empoderar personajes femeninos liberándolos de los límites impuestos por el marco de la pintura misma.

La representación del duelo plasmada en la pintura expresa el deseo de Elmer por inmortalizar a su hija. Este retrato familiar de 1890 muestra al artista y a su familia en frente de la casa que él y su hermano habían construido en Massachusetts en 1875. El objeto plástico se destaca por sus intrincados detalles y el contraste entre la familia de luto, que se sienta en una oscuridad relativa, y la hija muerta, que está bañada por la luz del sol. Como se mencionó anteriormente, Mourning Picture hace referencia a la muerte de Effie. Se cree que el dolor de esta pérdida abrumó tanto a los padres que decidieron abandonar la casa; por lo que la pareja empacó los juguetes de la niña y regaló a sus mascotas. Pero antes de irse, Elmer sintió que también necesitaba recordar, así que pintó este cuadro extraño y lleno de angustia, donde plasmó por última vez una escena familiar que incluía también a su hija fallecida.

Al principio, la pintura parece un ensueño de verano pintado por la mano de un artista inexperto, pero talentoso y meticuloso para los detalles, lo cual describe la obra plástica de Elmer. Se puede observar la hierba, las hojas individualizadas de los árboles, las sombras nítidas: todo el efecto es impresionante. De hecho, la pintura recuerda el estilo de los prerrafaelistas, con rasgos de corte surrealista como los de Magritte y Dalí.

Una pintura es una representación del espacio. En la obra de Elmer, la composición pictórica está perfectamente equilibrada. Del lado derecho se encuentran los padres y la casa familiar y del lado izquierdo Effie con sus animales amados. Dos juguetes se encuentran ubicados en la zona inferior derecha cerca de la niña. Exactamente en el centro de la composición, hay un árbol pequeño y delgado que divide ambos mundos: el de los vivos y el de los muertos. Este árbol funciona como un eje que establece líneas imaginarias alrededor del cual se distribuyen los elementos de la pintura. Esta composición de dos mitades contrasta la luz del sol primaveral con suaves colinas y una zona sombría frente a una casa de madera con ventanas cerradas. En el primer plano de la izquierda se encuentra la niña con las manos sobre un cordero, mientras que a la derecha su figura está equilibrada compositivamente por una madre y un padre vestidos para un funeral. La distribución de los cuerpos crea un sentido de equilibrio en el objeto plástico. 
Analizando el plano derecho, se observan los padres muy cerca de la casa. Las ventanas de la segunda planta están cerradas como si nadie habitara ahí. Los padres vestidos de negro absoluto están sentados en sillas de madera y no muestran ningún tipo de emoción; sus caras impávidas están pálidas. Él sostiene un periódico cerrado y ella un objeto que parece ser una taza. Ambos tienen la mirada perdida sin enfocar nada específico. En el plano inferior hay juguetes de la época: un cochecito de mimbre con una muñeca y un sombrero con un lazo rojo sobre la hierba. Estos elementos son los únicos que tienen color y ofrecen contraste con el paisaje que tiene colores opacos como el beige, verde musgo y café. Significativamente, estos juguetes son los objetos amados de la niña muerta. La madre se posiciona bajo las sombras de un arbusto, como cubriéndose de los rayos del sol. Este es un arbusto de flores conocidas como lilas de color lavanda, que están relacionadas con el amor y la muerte. Se puede apreciar que la figura materna es la que está más en la sombra en comparación con su esposo y su hija. Esto puede estar relacionado al dolor que la muerte de la niña le ha causado y al estado sombrío en que se encuentra.

La imagen de la casa es importante como emblema de la familia. De hecho, la construcción se impone en la mitad del espacio superior derecho de la pintura. Esta estructura está cerca de los padres, detrás de ellos para ser exactos, como si de alguna manera los representara. Esta cercanía puede sugerir que ellos son ahora los únicos habitantes del inmueble. El tamaño y diseño de la casa evidencia la condición económica estable de la familia, ya que es grande y de buena apariencia; lo que podría explicar en parte el impacto de la muerte de la única hija de una familia de clase media alta. La casa tiene colores apagados como el café claro y el gris, que transmiten monotonía y pasividad. Al mismo tiempo, la casa es un símbolo de la historia familiar y herencia que en este caso se ve frustrada por la muerte prematura de Effie. La construcción se percibe como una casa vacía, un recuerdo doloroso de una familia dividida.

Analizando el lado izquierdo de la pintura, se observa a Effie de pie a cierta distancia de los padres. Ella viste un atuendo de rayas de colores que contrasta con la vestimenta negra y solemne de sus padres. Hay un gato pequeño y un cordero. El cordero oculta una pierna de la niña lo que la hace ver extraña, como si le faltara una extremidad y estuviera incompleta. Los animales se relacionan con la noción de inocencia, especialmente el cordero blanco que la niña sostiene, relacionado tradicionalmente con los niños y la pureza. Asimismo, el cordero blanco es un símbolo de sacrificio y expiación. La imagen de la niña y su cordero refuerza la idea de una infancia perpetua, ya que Effie no pudo crecer.

Contrariamente al plano derecho, el izquierdo, donde Effie se posiciona tiene colores vivos como el vestido que ella porta y la presencia de luz. Aunque su cara es seria y sin expresión, sus mejillas están rosadas y tanto ella como sus mascotas parecen estar iluminados por el sol. La figura de la niña está en un 
primer plano y constituye lo que se conoce como el «centro visual» de la obra, ya que es lo que llama la atención del espectador de inmediato. Su tamaño es relativamente grande y su mirada dirige al espectador hacia sus padres, sentados en las sombras. A sus pies se observan las únicas flores de la escena familiar, son pequeñas flores silvestres de colores pastel. Esta interacción y contraste de colores crea lo que se conoce como «tensión dinámica», efecto que produce movimiento en el objeto plástico. Aunque a primera vista parece que la obra de arte solo hubiera representado a una familia en su rutina diaria, después de examinarla detenidamente, el espectador se da cuenta de que, tanto los padres como la hija, tienen expresiones sombrías en sus caras. La pintura se torna misteriosa y sus habitantes, por su extrema pasividad y falta de expresividad, asemejan fantasmas más que seres vivientes; creando una atmosfera lúgubre en la escena.

La naturaleza incorporada en el objeto plástico es escasa; se aprecian algunos árboles pequeños y delgados típicos de la región de Nueva Inglaterra. Hay algunas colinas de baja altura en el fondo de la pintura que se perciben detrás de la figura de la niña. Los colores que predominan son el verde, en diferentes tonalidades, tales como el verde musgo y verde claro. La línea monocromática de la casa y los verdes del paisaje son colores apagados, que presentan pocos contrastes y transmiten tristeza y opresión. El único elemento de cambio se encuentra en el cielo celeste claro que sirve de fondo. Hay algunas nubes blancas en el cielo, parece ser un día primaveral lleno de luz y claridad, lo que contrasta con el resto del texto pictórico.

De acuerdo con Elizabeth Young en su artículo «Mourning Picture and Magic Glasses», la pintura de Elmer contiene la mayoría de los elementos conocidos en inglés como «uncanny» que se puede traducir como «extraño» o «raro»: «the house with the darkened Windows (...) is a domestic space made strange; the doll, with its vacant stare, straddles the line between animate and inanimate. Even the Lamb seems uncanny» ${ }^{17}$. La combinación de objetos animados e inanimados es en parte responsable de la atmosfera lúgubre que permea la escena. El espacio doméstico y familiar se vuelve extraño y ajeno. Young también se refiere a la representación de la niña como una figura que habita dos mundos: el de los vivos y el de los muertos de manera simultánea: «the waxy face, stiff body, and formal dress of Effie Elmer evoke the nineteenth-century postmortem photograph» ${ }^{18}$. Para Young, la representación de la niña, por la rigidez de su cuerpo y la formalidad de su vestido, asemeja una foto post mórtem, lo cual era una costumbre de la época para preservar el recuerdo de un ser querido. Aunque se sabe que Elmer pintó a su hija basándose en una vieja fotografía suya y que no existen de la niña este tipo de retrato; sin haberlo

17 Elizabeth Young, «Mourning Pictures and Magic Glasses [The First of Two Parts]», The Massachusetts Review 54, n. ${ }^{\circ}$ (2013): 549.

18 Ibíd., 550. 
planeado la imagen de Effie en la pintura se convierte de hecho en su «fotografía post mórtem».

Quizás el efecto más extraño en la pintura es el craquelado, o el crujido como una telaraña, en las nubes. Esto ocurrió por accidente, y como resultado de que la pintura blanca se secara más rápido ya que contenía menos aceite. Este efecto aumenta la atmósfera temblorosa de la imagen de extrema fragilidad y dolor fragmentado. Paradójicamente, aunque Effie está muerta, su representación tiene más luz y color que la de sus padres. Conjuntamente, hay objetos importantes relacionados con ella como sus juguetes favoritos y sus mascotas; que funcionan como elementos metonímicos que la representan en su ausencia. Se da también una fijación o suspensión del tiempo. La inmovilidad y falta de expresión de los personajes del cuadro crean una fijación del momento del duelo como si el reloj se hubiera detenido ahí para siempre, de la misma manera en que se había detenido para la niña.

Por lo analizado en los párrafos anteriores, se puede afirmar que el momento de luto es representado en el objeto plástico como una inversión de roles: los padres parecen estar muertos mientras que la hija está aún viva. La muerte emocional de los padres los lleva a la total inmovilidad y falta de expresión. El luto los coloca en un estado sombrío donde no hay color, movimiento ni vida. El recuerdo y los objetos amados de ese ser que ya ha partido son vitales en su proceso de retorno. Aunque distante y etérea, Effie es el único miembro de la familia que parece tener vida en la pintura, físicamente ausente pero viva en los recuerdos de sus padres. El deseo de Elmer se cumple en su creación, ya que logra materializar e inmortalizar a su hija, fijándola en el tiempo y en el objeto plástico. En la quietud de la imagen, Effie queda atrapada para siempre a la edad de su muerte. Ella permanece anclada al lugar donde una vez jugó con sus mascotas y juguetes, incapaz de estar con sus padres, quienes solo pueden sentarse y recordar.

En contraste con la pintura que expresa el deseo del pintor por inmortalizar a su hija, la re-presentación del duelo en el poema Mourning Picture expresa el sueño de Effie. A través de su poema ecfrástico, Adrienne Rich establece un diálogo con la pintura previamente analizada, transformando a la niña, quien deja de ser un objeto plasmado para convertirse en un sujeto creativo. Como afirma Irene Artigas Albarelli en su artículo «Remediar el género: écfrasis, museos y autor(a)referencia»:

Alguien observa algo y escribe sobre eso que observó. Su mirada selecciona lo que le impresionó de la obra, lo que incluirá en su escritura, lo que quiere decir sobre ella. Su propio discurso se coloca junto al de la obra artística y quien lee reconoce esas dos voces que a veces corren 
paralelas y a veces enfrentadas. Debido a su estructura y su carácter derivado, la écfrasis incluye necesariamente este dialogismo. ${ }^{19}$

Dentro de esta relación dialógica con el objeto plástico, la mirada de Rich se posa sobre Effie, la cual se convierte en la voz que narra la escena pictórica. En su nuevo rol de sujeto lírico, la niña muerta reconoce los objetos que antes formaban parte de su cotidianidad, como los muebles de su casa. Asimismo, distingue a sus padres vestidos de luto: «They have carried the mahogany chair and the cane rocker/out under the lilac bush/and my father and mother darkly sit there, in black clothes» (1-3). El uso del adverbio «darkly» (triste 0 misteriosamente) acentúa la atmósfera funesta que permea la escena.

Como reconocida feminista que era, Rich recurrió a la poesía ecfrástica como una manera de desarticular estructuras patriarcales de representación de las relaciones de poder, conocimiento y deseo. Rich concibe la écfrasis como un proceso de re-vision o tener una nueva visión: «Re-vision -the act of looking back, of seeing with fresh eyes, of entering an old text from a new critical direction»20. Al tener una voz, Effie deja de ser la figura femenina tradicionalmente silenciada por la sociedad, por su padre y, finalmente, por la muerte, para convertirse en el centro de la construcción de sentido de la pintura y del duelo representado ahí. Significativamente, Effie es la única voz en el poema. Sus padres, por otro lado, continúan sentados en sus sillas en completo silencio.

Además de tener voz, la niña muerta adquiere la capacidad de ver y describir la escena plasmada en la pintura. Esta nueva «mirada» le permite observar y recrear el objeto plástico. Por medio de una especie de «desdoblamiento», Effie puede liberarse del cuadro de su padre y describir el texto pictórico desde «afuera»: «Our clapboard house stands fast on its hill/ my doll lies in her wicker pram/ gazing at western Massachusetts» (4-6). El uso de pronombres posesivos como «our»y «my» evidencia este nuevo dominio de las cosas que pasan a ser de su propiedad.

La nueva voz y mirada de Effie evidencian un proceso de empoderamiento entrelazado a un estado de autonomía. En el texto poético, se encuentran dos ejemplos donde este nuevo rasgo es notorio: «I am Effie; visible and invisible/ remembering and remembered» (19-20). El uso del verbo «ser» en tiempo presente refuerza el proceso de consolidación de identidad anclado al momento presente, lo que contradice el hecho de Effie ya no esté viva. Paradójicamente, la niña se describe a sí misma como «visible» ya que existe en el poema, pero «invisible» ya que ha muerto. Esta dualidad es expresada también en la habilidad que tiene de recordar y ser recordada. El hecho de que el verbo «recordar» sea usado en presente progresivo indica que este proceso no ha

\footnotetext{
19 Irene Artigas Albarelli, «Remediar el género..., 166.

${ }^{20}$ Marta Soares, «Language Cannot Do..., 4.
} 
finalizado, lo que refuerza la idea de que Effie siga de alguna manera presente. Asimismo, al final del poema, el sujeto lírico repite la misma afirmación: «I am Effie...» (32), ratificando su identidad, desafiando al tiempo y a la muerte.

La nueva identidad de Effie se manifiesta a través del poder creativo adquirido, el cual le permite reconstruir el paisaje de la pintura: «l could remake each shaft of grass/ feeling its rasp on my fingers,/ draw out the map of every lilac leaf/ or the net of veins on my father's/ grief-tranced hand» (8-12). El uso del condicional «could» junto al verbo «remake» revela el poder creativo que el yo lírico ha adquirido. Es como si la niña conociera de memoria cada hoja, cada flor del jardín; inclusive la mano venosa de su padre doliente, la cual es comparada con las venas de las hojas de los árboles. De hecho, los recuerdos juegan un papel importante en este proceso de re-creación del objeto plástico. Ocurre de esta manera, una inversión de roles: ahora es la hija la que tiene el poder de «pintar» la mano de su padre en luto, así como los objetos de su cotidianidad, convirtiéndose en el artífice del momento plasmado.

Este proceso creativo está presente en varias secciones del poema. La segunda estrofa inicia enfatizando este nuevo poder: «Out of my head, half-bursting,/ still filling, the dream condenses--/ shadows, crystals, ceilings, meadows, globes of dew» (13-15). Un listado de objetos y posibilidades emerge de los sueños del yo lírico revelando que su capacidad creativa es ilimitada: «Could I give back the leaf its skeleton, the air/ its early-summer cloud» (29-30). Es a través del recuerdo y la narración, que Effie puede reconstruir el texto pictórico desde una perspectiva personal y poderosa. El poema termina con una oración reveladora: «l am Effie, you were my dream» (énfasis de la autora del artículo). De acuerdo con Marta Saores en su artículo «Language Cannot Do Everything»:

The poem succeeds in transferring the creator's authority from father to daughter, for the scene is now a projection of Effie's dream, located on the reverse of Elmer's painting .... Effie becomes the vanishing point where opposites meet, the subversive creator who finds herself as such in the realm of ekphrastic poetry. ${ }^{21}$

De esta manera, el poema logra transferir la autoridad creativa del padre a la hija, ya que la escena es ahora una proyección del sueño de Effie, ubicado en el reverso del cuadro de Elmer.

Marta Soares afirma que en el poema de Rich, la muerte no limita a Effie sino, por el contrario, le da una fuerza omnipresente que le permite relacionarse con el tiempo pasado y futuro simultáneamente:

21 Ibíd., 27. 
Instead of dictating Effie's absence, death translates her into a powerful omnipresence endowed with omniscience; in the poem she is fully knowledgeable of the past («This was our world»), and then future («They will move from the house»). Empowered by death and by the poem, Effie finds the strength to challenge her father's authority as maker of the painting. ${ }^{22}$

Paradójicamente, son el texto poético y la muerte misma las que empoderan a Effie, permitiéndole recrear su propia versión de la pintura: «No longer entrapped in Elmer's painting, Effie claims agency as creator by threatening to remake his work and make it her own: "Should I make you, world, again"» 23 .

El poema de Rich es totalmente descriptivo construido a partir de imágenes visuales, lo que emula el efecto de una pintura en el espectador. Las imágenes del poema son vívidas y dibujan elementos de la casa familiar. En la primera estrofa se describen con detalle ciertos objetos especificando los materiales de los que están fabricados: la silla es de «caoba», la mecedora de «caña» y el coche de la muñeca es de «mimbre». La segunda estrofa dibuja los colores y la luz de esa mañana de verano: «Under the dull green of the lilacs, out in the light/ carving each spoke of the pram, the turned porch-pillars,/ under high earlysummer clouds» (16-18). Hay colores como el verde y el violeta de las flores, la presencia de la luz y las nubes de principio de verano. En esta imagen encontramos referencia a las columnas torneadas del pórtico o entrada de la casa. Este espacio liminal nos recuerda la condición misma de Effie, que no solo se mueve entre dos medios, pintura y poema, sino también entre dos mundos.

A través de la voz y la mirada de Effie, la escena de duelo se convierte en una suerte de sueño en el cual ella puede «pintar» escenas familiares y objetos amados. Liberada del cuadro y del recuerdo de su padre, la niña construye un sentido de identidad y autonomía que le permite redefinirse por medio del poder creativo de las palabras. Mediante un proceso introspectivo, el sujeto lirico puede reflexionar acerca de lo que fue, lo que es y lo que pasará después de su partida. Contrario a la fijación del momento que encontramos en el objeto plástico, en el poema la niña se mueve en un tiempo que no se detiene, sino que fluye eternamente. El sueño de Effie se concretiza en el poema, atravesando el deseo de su padre plasmado en la pintura.

22 Ibíd..

23 Ibíd., 28. 


\section{Conclusiones}

Para Effie: Antes de volver a nacer, tienes que morir.

Salman Rushdie

En esta relación dialógica que ocurre entre el objeto plástico y el texto poético se aprecian ciertas semejanzas y diferencias en sus aproximaciones respectivas a la experiencia de la muerte y el duelo. La principal similitud es el rol protagónico de Effie en ambos textos. La pintura de Elmer coloca a la niña en el centro visual de su creación, en oposición con la representación de los padres que ocupan un espacio secundario. Esto es logrado por medio de recursos pictóricos basados en una dinámica binaria que contrasta el uso de colores opacos y vivos, la presencia-ausencia de la luz y el posicionamiento en un plano principal o subordinado de los diferentes personajes y objetos de la pintura.

De manera similar, en el texto poético de Rich, Effie es la mirada que observa y la voz que narra la escena familiar. Empoderada por la muerte y liberada del marco de la pintura de su padre, la niña se convierte en la creadora de significado de esta. Por medio de la palabra, Effie adquiere el poder de reconstruir todo lo que ve: «shadows, crystals, ceilings, meadows, globes of dew» (15). Se puede afirmar que Effie se posiciona en el centro de ambas representaciones ya que es a partir de ella que se construye sentido. Paradójicamente, la ausencia de la hija es la que se transforma en presencia dominando pintura y poema. Effie no solo está viva; sino que alcanza la inmortalidad a través de ambas representaciones.

El protagonismo de la niña se encuentra ligado a la inversión de roles que ocurre en ambos textos. En la pintura, es la niña muerta la que es representada viva mientras sus padres parecen haber muerto. De igual manera, en el texto poético, Effie es la fuerza creadora que desplaza a su padre, quien se convierte en un elemento más de su sueño. Morir o vivir, crear o ser creado; dos momentos entrelazados en las representaciones de Mourning picture.

Tanto el texto poético como el visual hacen referencia a ciertos objetos, como juguetes y mascotas, que son usados con un sentido metonímico de Effie y su inocencia. Asimismo, hay elementos de la casa familiar como muebles y la naturaleza típica de Massachusetts que están presentes como parte de la cotidianidad que los unía como la familia que ya no son. La luminosidad que rodea a Effie en la pintura se encuentra también en el poema por medio de imágenes visuales que aluden a colores y a la presencia de la luz como parte de su mundo. 
Interesantemente, la principal diferencia entre los textos analizado remite a Effie de nuevo y a las maneras en que es representada. Como se expuso anteriormente, Effie experimenta un proceso de metamorfosis, ya que deja de ser una proyección del dolor de su padre para desarrollar un sentido de identidad, convirtiéndose en el yo lírico del poema que sueña la escena del luto de su propia muerte.

Otra diferencia entre los textos analizados es su aproximación al tiempo. En el poema, Effie desafía no solo a su padre y a la muerte, sino también al tiempo: «They will move from the house,/ give the toys and pets away./ Mute and rigid with loss my mother/ will ride the train to Baptist Corner» (21-24). En un acto de anticipación a los hechos, Effie puede predecir las acciones y emociones de sus padres, como parte de una realidad de la cual ya ella no forma parte. De la mima manera puede volver al pasado a contemplar la casa y decir: «this was our world» (7). Contrario a la fijación del tiempo que encontramos en el objeto plástico, que exhibe una realidad congelada en el lienzo, en el poema el tiempo puede fluir libremente.

La relación dialógica que sucede a partir del proceso de écfrasis abre un espacio donde padre e hija pueden conversar acerca del momento doloroso que significa la muerte y la experiencia del duelo que esto ocasiona, creando múltiples significados y significantes. Como afirma Pimentel en «Écfrasis y lecturas iconotextuales»: «la écfrasis misma, en tanto que lectura/escritura del texto visual modifica nuestra percepción del objeto plástico, reorganiza nuestra mirada y la jerarquiza de acuerdo con los valores establecidos por el texto verbal» 24 . En esto radica la riqueza del ejercicio de la écfrasis, en redireccionar miradas y construir pactos intertextuales e intermediales, de los cuales el lector/ investigador es un participante activo.

Como texto ecfrástico, el poema no re-presenta, sino que re-significa al objeto plástico al entrar en una red textual y contextual diferente, construida por la visión de la poeta. Pintura y poema se miran frente a frente. En la primera, un recuerdo doloroso fijado en una imagen; en el segundo, una narradora/ protagonista que cuenta su historia de morir. Al final, los dos comparten un elemento esencial: una niña que nos mira, nos inquieta y cuestiona acerca de la muerte y el luto volviéndose inmortal en el arte.

24 Pimentel, «Écfrasis y lecturas..., 208. 


\section{Formato de citación según APA}

Molina-Espinoza, I. (2021). Muerte y luto en Mourning picture: conversaciones entre un pintor y su hija. Revista Espiga, 20 (42), 147-168.

Formato de citación según Chicago-Deusto

Molina-Espinoza, lleana. «Muerte y luto en Mourning picture: conversaciones

entre un pintor y su hija?». Revista Espiga 20, n. 42

(julio-diciembre, 2021): 147-168. 


\section{Referencias}

Artigas Albarelli, Irene. «Remediar el género: ecfrasis, museos y autor(a) referencia». Interférences littéraires/Literaire interferenties. (2017): 163184.

Bárzaga Morales, Iraida Lisandra. «Lectura iconotextual: Ia écfrasis metaléptica como recurso representacional en Una Novelista en el Museo del Louvre, de Zoé Valdés». Revista Comunicación 27, n. ${ }^{1}$ (2018): 19-34. https://www.scielo.sa.cr/pdf/com/v27n1/1659-3820-com-27-0119.pdf.

Lovell, Susan. «Ekphrasis as an Analytical Mode in Biography: Finding Vida. Lahey's Romantic Character». Auto/Biography Studies 28, (2013): 273-295.

Mansilla Blanco, María Isabel. «Descripción prosódica de la poesía de Adrienne Rich: 1951-1999». Tesis doctoral. Universidad de Valladolid, 2001. https://dialnet.unirioja.es/servlet/tesis?codigo $=178234$.

Pimentel, Luz Aurora. «Écfrasis y lecturas iconotextuales». Revista de teoría literaria y literatura comparada Poligrafías, n. ${ }^{\circ}$ (2003): 205-218.

Plaza Velasco, Marta. «Poesía que es pintura. Écfrasis literaria en exposición de Olvido García Valdés». Actio Nova: Revista de teoría de la literatura y literatura comparada, n. ${ }^{\circ} 2$ (2018): 29-64. https:// www.scielo.sa.cr/pdf/com/v27n1/1659-3820-com-27-01-19.pdf

Rich, Adrienne. «Entre los poetas míos». Cuaderno n.ำ 10 de Poesía Social. OMEGALFA (2013). https://omegalfa.es/autores.php? letra $=\&$ pagina $=20 \#$

Rich, Adrienne. Poems. Classic Poetry Series. The Worlds' Poetry Archive, 2012.

https://nepantlerablog.files.wordpress.com/2016/02/the-dream-of-acommon-language-adrienne-rich.pdf

Soares, Marta. «Language Cannot Do Everything»: Ekphrasis as a Strategy of Re-vision in Adrienne Rich's Poetry». Conferencia pronunciada en 34th International ASAT en Alanya, Turquía, noviembre del 2010. 
Young, Elizabeth. «Mourning Pictures and Magic Glasses [The First of Two Parts]». The Massachusetts Review 54, n. 3 (2013): 539-55. http:// www.jstor.org/stable/24494528.

\section{Enlaces:}

http://archive.boston.com/ae/blogs/sebastiansmee/2011/06/

frame_by_frame_edwin_elmers_mo.html

https://dergipark.org.tr/tr/download/article-file/998431

https://poets.org/text/notes-ekphrasis

https://www.altillo.com/articulos/pintura_print.asp

https://www.newyorker.com/books/page-turner/adrienne-richs-poetictransformation

https://www.poetryfoundation.org/poets/adrienne-rich 


\section{Anexo 1}

\section{Pintura Mourning picture de Edwin Romanzo Elmer}

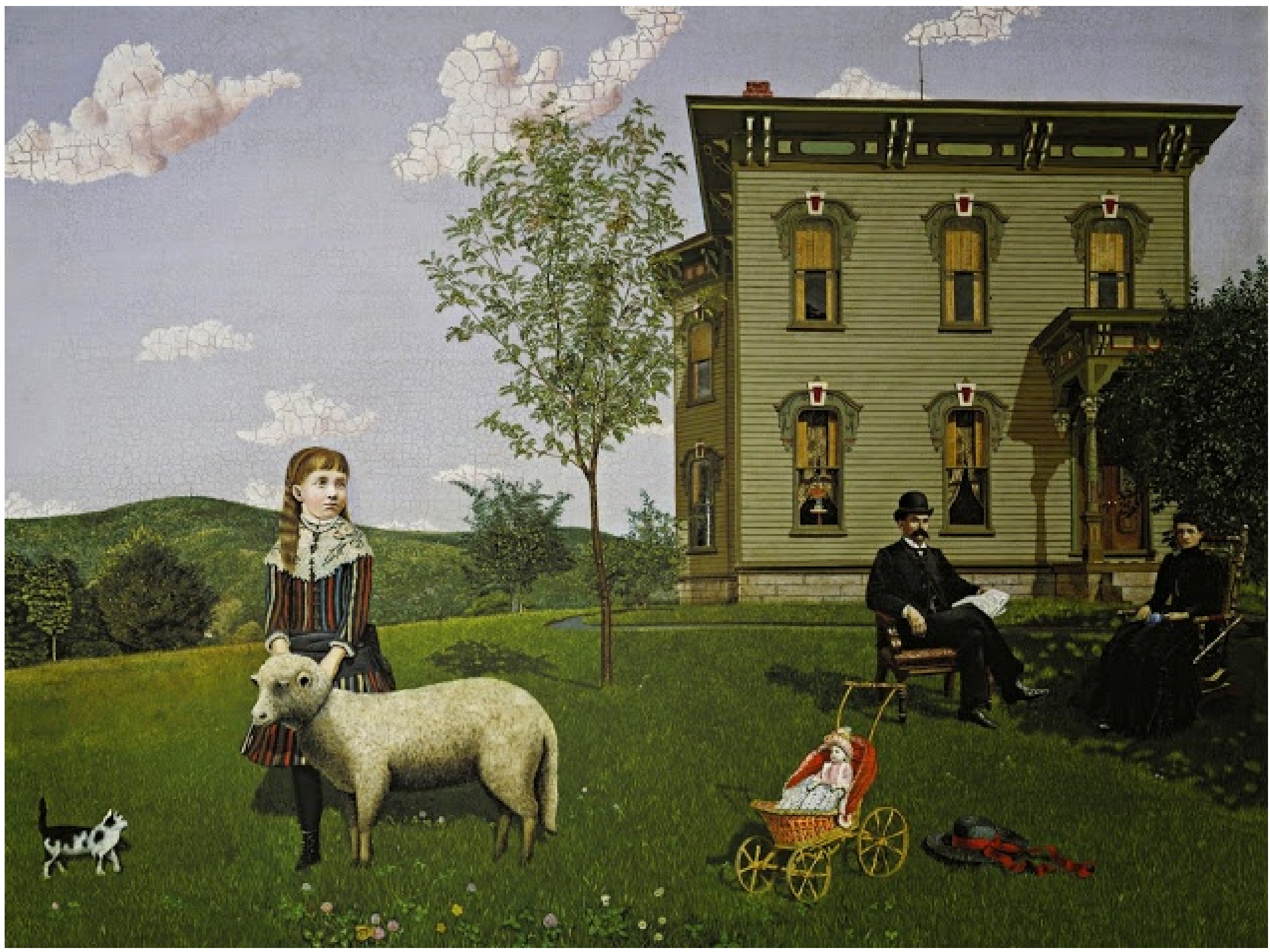

Mourning picture. Edwin Romanzo Elmer, 1850-1923. Smith College Museum of Art, Massachusetts.

Tomada de: https://www.ekphrastic.net/ekphrastic-journal/mourning-picture-byadrienne-rich 


\section{Anexo 2}

Poema Mourning Picture de Adrienne Rich

Adrienne Rich (1965)

(The picture was painted by Edwin Romanzo Elmer (1850-1923) as a memorial to his daughter Effie. In the poem, it is the dead girl who speaks).*

They have carried the mahogany chair and the cane rocker out under the lilac bush, and my father and mother darkly sit there, in black clothes. Our clapboard house stands fast on its hill, my doll lies in her wicker pram gazing at western Massachusetts.

This was our world.

I could remake each shaft of grass

feeling its rasp on $m$ fingers, draw out the map of every lilac leaf or the net of vines on my father's grief-tranced hand.

Out of my head, half-bursting, still filling, the dream condenses shadows, crystals, ceilings, meadows, globe of dew. Under the dull green of the lilacs, out in the light carving each spoke of the pram, the turned porch-pillars, under high early-summer clouds, I am Effie, visible and invisible, remembering and remembered.

They will move from the house, give the toys and pets away. Mute and rigid with loss my mother will ride the train to Baptist Corner, the silk-spool will run bare.

I tell you, the thread that bound us lies

faint as a web in the dew.

Should I make you, world, again, could I give back the leaf its skeleton, the air its early-summer cloud, the house its noonday presence, shadowless, and leave this out? I am Effie, you were my dream.

* La nota aclaratoria fue escrita por Rich. 


\section{Anexo 3}

Fotografía de lápida de Effie Elmer

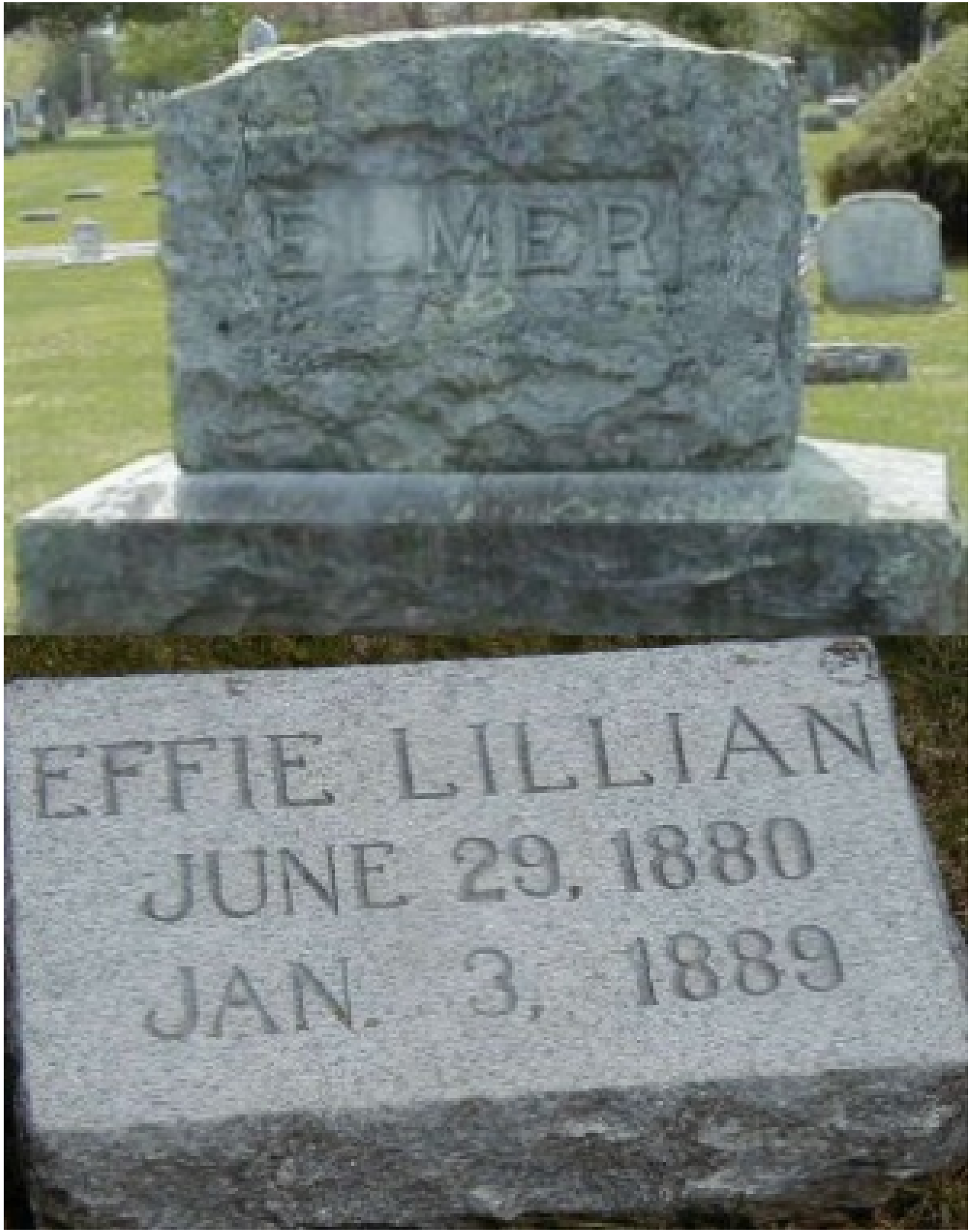

Arms Cemetery, Shelburne Falls, Franklin County, Massachusetts Tomada de: http://www.robertstrongwoodward.com/Scrapbook/ Bauerlein.html 